\title{
Innovations in research on social contexts of ageing
}

\author{
Dorly J. H. Deeg · Hans-Werner Wahl
}

Published online: 16 February 2008

(C) The Author(s) 2008

This editorial marks the first issue of the fifth volume of the European Journal of Ageing. We as editors are very happy to see that the Journal has reached this milestone. It shows that the Journal has proved viable, and fills a niche in the market of ageing-related journals. We owe this milestone in the first place to our expanding group of contributing authors. In 2007, we had 49 submitted manuscripts, and we were able to publish 26 articles. We are also pleased to note that the number of countries where the authors were based increased. In particular, we had contributions from southern Europe (Verropoulou and Tsimbos 2007) and eastern Asia (Yeung and Fung 2007). This fits in with our goal to recruit high-quality research papers from countries outside northern and western Europe, from which regions most publications still originate.

Also, we have an expanding group of active readers, which can be observed from the number of times articles published in the Journal have been cited in other Journals than the EJA. This number was 16 at the end of 2006, and was up to 56 at the end of 2007. A provisional calculation of the impact factor shows that this indicator amounted to 0.40 for 2006, and 0.97 for 2007. The best cited article, with 11 citations in journals other than the EJA, was the overview of the ENABLE-AGE project (Iwarsson et al.

\section{J. H. Deeg ( $ه)$}

VU University Medical Center, Van der Boechorststraat 7, 1081 BT, Amsterdam, The Netherlands

e-mail: eja@vumc.nl

\section{H.-W. Wahl}

Institute of Psychology, Department of Psychological Ageing

Research, University of Heidelberg, Bergheimer Strasse 20,

69115 Heidelberg, Germany

e-mail: eja@psychologie.uni-heidelberg.de
2004). Just when finalising this Editorial, we had the excellent news that the Journal has been accepted by ISI. This opens the door to indexing EJA articles in scientific databases and measuring their impact and influence on future research. The ISI decision was based on among others: "the Journal's excellent quality, timely publication, the international diversity and the fact that it is of great regional importance."

Although these facts are quite satisfactory, we will continue to work on increasing the impact of the EJA on the gerontological research community. One upcoming event will certainly have our attention: the 19th congress of the International Association of Gerontology and Geriatrics, in July 2009 in Paris. This will be a high-profile event for the international gerontological community. Our publisher is already preparing for this event in order to highlight the role of our Journal in this community.

Going from numbers to substance, it remains our mission to contribute to the understanding of ageing in Europe and the world over. Our main tool is the publication of research reports, either as single publications or in thematic special sections. In the year 2008 , we plan to address in special sections two themes that we feel need attention: the relation between unhealthy lifestyles and disability, and midlife determinants of mental health and implications for old age. In the section Critical Issues in Ageing Research, we will invite one or more contributions that present widerranging expert opinions on aspects of the state of the art in gerontology. In addition, we have been asked by editorial board members to open a section on book reviews. As very many books on research on ageing are being published, it will not be possible to provide a comprehensive overview of recent books, or even to select the most important ones. However, we will start to invite thematic essays based on a couple of recent books by experts in the field. 
In the current issue, we bring together seven articles which in one way or other all focus on the social context of ageing.

The first article, by Gaymu et al. (2008), provides important data on "Future trends in health and marital status: effects on the structure of living arrangements of older Europeans in 2030". In the year 2030, in most western countries the percentage of older persons in the population will have reached its maximum. This study brings the positive news that more older people will live in couples than nowadays. Both men and women aged 85 and over will be less likely to live alone or in institutions. The authors show that expected trends in marital status (widowhood and divorce) have more influence on living arrangements than expected changes in health status.

Two contributions focus on another aspect of close family relations: the relation between children and their ageing parents. The contribution by Van Gaalen et al. (2008) on "Intergenerational contact beyond the dyad: the role of the sibling network" introduces a usually neglected factor in research on parent-child contacts: the network of brothers and sisters. Indeed, characteristics of this network influence the extent of support a child gives to its parent. It is good to see that there is now a panel study that includes data in sufficient detail so as to provide such innovative findings. The work of Buber and Engelhardt (2008) titled "Children's impact on mental health of their older mothers and fathers. Findings from the SHARE" adds to the already existing series of papers in the EJA on recent results of the Survey of Health, Ageing and Retirement in Europe. A positive relation was found between the simple existence of children as well as contacts with children with mental health, such that childless individuals and those with fewer contacts showed higher depressive symptoms. As is also shown, findings deserve qualification in cultural terms. For example, in southern Europe children leave the parental home at a very late age as compared to Nordic countries.

The article by Savla et al. (2008) on "Home help services in Sweden: responsiveness to changing demographics and needs" addresses an important issue of care provision, i.e., predictors of home help coverage rates and rates of institutionalisation in Sweden between 1994 and 2000. Findings reveal, for example, that decreases in coverage rates were greater in municipalities with a higher proportion of unmarried elders, greater ratio of older women to men, with more home help staff workers, and more expensive services. Rates of institutional living were higher in municipalities that spend more on old age services and with a greater portion of unmarried elders.

Two reports from intervention studies focus on the optimalisation of health and social services. The study by Rodenas et al. (2008) targeting "Case management method applied to older adults in the primary care centres in
Burjassot (Valencian region, Spain)" adds to emerging picture of positive outcomes of community-oriented interventions from a Spanish perspective. The EJA already has paid attention to this theme from the Danish perspective (see special section on prevention home visits in issue $4 / 3$ of 2007) and in this issue we publish a further study based on the Danish experience. The article by Vass et al. (2008) titled "Preventive home visits to home-dwelling older people and hospital admissions: a municipality-randomised intervention trial" shows that interdisciplinary education of preventive home visitors and general practitioners lowers the use of acute hospital care in specific groups of community-living older persons.

Finally, the research by Kalfoss et al. (2008[e1]) on "The suitability of the WHOQOL-BREF for Canadian and Norwegian older adults" furthers the growing data body on the psychometrics of a now widely applied quality of life measurement device, the WHOQOL-BREF. Partial support for the overall construct validity of the measure in older adults was found, but there was also reason to assume that cultural differences play a role and must be considered in the evaluation of the detected psychometric properties and respective differences between countries.

This collection of articles shows the wide scope of ageing research, this time highlighting the social context of ageing with a number of innovative study reports. At the same time, these studies show the practical use of research on the social context of ageing. The contributions with an international comparative focus, in turn, provide a warning that we should be wary to generalise findings from single studies across time and place. It is exactly such warning that brings the field of ageing research ahead.

Open Access This article is distributed under the terms of the Creative Commons Attribution Noncommercial License which permits any noncommercial use, distribution, and reproduction in any medium, provided the original author(s) and source are credited.

\section{References}

Buber I, Engelhardt H (2008) Children's impact on mental health of their older mothers and fathers. Findings from the SHARE. Eur J Ageing 5(1). doi:10.1007/s10433-008-0074-8

Gaymu J, Ekamper P, Beets G (2008) Future trends in health and marital status: effects on the structure of living arrangements of older Europeans in 2030. Eur J Ageing 5(1). doi:10.1007/ s10433-008-0072-x

Iwarsson S, Wahl H-W, Nygren C (2004) Challenges of crossnational housing research with older people: lessons from the ENABLE-AGE project. Eur J Ageing 1(1):79-88

Kalfoss, Low, Molzahn (2008) The suitability of the WHOQOLBREF for Canadian and Norwegian older adults. Eur J Ageing 5(1). doi:10.1007/s10433-008-0070-z

Rodenas F, Garces J, Carretero S, Megia MJ (2008) Case management method applied to older adults in the primary care centres in Burjassot (Valencian region, Spain). Eur J Ageing 5(1) 
Savla J, Davey A, Sundström G, Zarit SH, Malmberg B (2008) Home help services in Sweden: responsiveness to changing demographics and needs. Eur J Ageing 5(1). doi:10.1007/s10433008-0071-y

Van Gaalen RI, Dykstra PA, Flap H (2008) Intergenerational contact beyond the dyad: the role of the sibling network. Eur J Ageing 5(1). doi:10.1007/s10433-008-0076-6

Vass M, Hendriksen C, Thomsen JL, Parner ET, Avlund K (2008) Preventive home visits to home-dwelling older people and hospital admissions: a municipality-randomised intervention trial. Eur J Ageing 5(1). doi:10.1007/s10433-007-0069-x

Verropoulou G, Tsimbos C (2007) Socio-demographic and healthrelated factors affecting depression of the Greek population in later life: an analysis using SHARE data. Eur J Ageing 4(3): $171-181$

Yeung GTI, Fung HH (2007) Social support and life satisfaction among Hong Kong Chinese older adults: family first? Eur J Ageing 4(4):219-227 